\title{
Desenvolvimento de uma massa funcional pronta para tortas utilizando o método de Desdobramento da Função Qualidade (QFD)
}

\author{
Developing a functional ready to bake dough for pies using the Quality Function Deployment (QFD) method
}

Ana Luisa Daibert PINTO ${ }^{1 \star}$, Caroline Liboreiro PAIVA ${ }^{1}$

\begin{abstract}
Resumo
Grande parte das indústrias alimentícias no Brasil tem encontrado na inovação de produtos a chave para a sobrevivência no mercado. Uma forte tendência é o lançamento de produtos que, além da alta qualidade sensorial e nutricional, apresentem benefícios associados à saúde, os denominados alimentos funcionais. Dentre os funcionais, se encontram os ingredientes prebióticos, que, quando presentes na dieta, estimulam seletivamente o crescimento e a atividade de espécies bacterianas promotoras da saúde do organismo. O presente trabalho teve como objetivo desenvolver uma massa funcional pronta para tortas, utilizando-se como prebiótico, a inulina. O desenvolvimento desse produto foi baseado na ferramenta QFD (Desdobramento da Função Qualidade), sendo esta apontada como meio de organizar o desenvolvimento de novos produtos principalmente no nível de protótipos. Para tal desenvolvimento, pesquisas, testes e análises sugeridas pelo QFD foram realizados. De acordo com os resultados da matriz da qualidade obtida, concluiu-se que as características que os consumidores atribuem como de maior importância para a massa são: ser funcional, não quebrar, ter sabor neutro e ter diâmetro e espessura uniformes. Consequentemente, estas foram priorizadas no desenvolvimento do produto. A análise sensorial indicou que os provadores gostaram muito de todos os atributos de qualidade da massa. Por outro lado, o QFD mostrou-se eficaz no sentido de direcionar, de forma prática, a maneira de planejar e conduzir as atividades necessárias ao processo de desenvolvimento do produto.
\end{abstract}

Palavras-chave: desenvolvimento de novos produtos; alimento funcional; inulina; QFD.

\begin{abstract}
Great part of the food industries in Brazil have found that the key for surviving in the market is the innovation of products. A new trend is the launching of products which besides having high sensorial and nutritional quality, they also present benefits associated with health, and are known as functional food. Among these products are the prebiotics, food ingredients that stimulate the growth and activity of bacteria which are beneficial to the health of the body. The aim of the present work is the development of a functional ready to bake dough for pies using inulin as a prebiotic. The development of this product was based on the tool QFD (Quality Function Deployment), and it was presented as a means to organize the development of new products, especially prototypes. Hence, studies, tests, and analysis suggested by the QFD were undertaken. According to the results of the matrix of quality obtained, it can be said that the characteristics that the consumers attribute as the most important for baking dough are: be functional, do not shatter, have a neutral flavor, and present uniform diameter and thickness. Consequently these characteristics were prioritized during the development of the product. The sensorial analysis indicated that the tasters really enjoyed all the quality attributes of the dough. On the other hand, the QFD proved useful for planning and conducting the necessary activities for the process of developing the product.
\end{abstract}

Keywords: development of new products; functional food; inulin; method QFD.

\section{Introdução}

Já é consenso que a qualidade de vida está associada, entre outros fatores, ao estilo de vida e principalmente à qualidade da dieta que se consome. Daí o crescente interesse dos meios acadêmico e empresarial por um ramo da ciência e tecnologia de alimentos: o dos alimentos funcionais. Esses alimentos são assim denominados porque além das suas funções básicas relativas à nutrição, exercem uma potente atividade biológica e têm sido sugeridos como importantes meios de redução do risco de diversas doenças crônico-degenerativas, enfermidades inflamatórias e distúrbios metabólicos.

Dentre os compostos bioativos incluídos na categoria dos funcionais estão aqueles capazes de modular a microbiota do intestino, os prebióticos. A inulina tem sido designada como prebiótico e fibra alimentar solúvel por sua não digestibilidade pelas enzimas do trato digestivo humano, estímulo seletivo ao crescimento e à atividade de bactérias intestinais promotoras de saúde, especialmente as bifidobactérias. Ao mesmo tempo, a presença de bactérias indesejáveis, tais como a Clostridia, é reduzida significativamente. A inulina também influencia beneficamente os parâmetros lipídicos e demonstra efeitos positivos na absorção de cálcio, magnésio e fósforo, além de ter baixo valor calórico (OHTA et al., 1995; GIBSON; ROBERFROID, 1995).

Recebido para publicação em 1/2/2008

Aceito para publicação em 18/9/2008 (003182)

${ }^{1}$ Departamento de Ciências Exatas, Engenharia de Alimentos, Centro Universitário de Belo Horizonte, CEP 30455-610, Belo Horizonte - MG, Brasil,

E-mail: anadaibert@yahoo.com.br

${ }^{*}$ A quem a correspondência deve ser enviada 
No Brasil, a CTCAF - Comissão Técnico-Científica de Assessoramento em Alimentos Funcionais e Novos Alimentos (BRASIL, 1999), com base em evidências científicas, aprovou a seguinte alegação na rotulagem de produtos com inulina: "A inulina contribui para o equilíbrio da flora intestinal. Seu consumo deve estar associado a uma alimentação equilibrada e hábitos de vida saudáveis”. Esta alegação pode ser utilizada desde que a porção diária do produto pronto para consumo forneça no mínimo $3 \mathrm{~g}$ de inulina, se o alimento for sólido, ou $1,5 \mathrm{~g}$, se o alimento for líquido (BRASIL, 1998).

Além das propriedades promotoras de saúde, a inulina pode ser usada para obter efeitos tecnológicos e sensoriais em diversos produtos alimentícios. Não possui sabor desagradável e não aumenta a viscosidade dos alimentos; apresenta propriedades funcionais similares aos açúcares e xarope de glicose, podendo substituir gorduras, açúcares ou amido. $\mathrm{O}$ equivalente de dextrose (DE) da inulina varia de 20 a $25 \% \mathrm{~m} / \mathrm{m}$ (expresso como D-glucosa sobre peso seco) e seu poder adoçante corresponde de 30 a $65 \%$ do da sacarose. Por apresentar cerca de um terço do poder adoçante da sacarose e não ser calórica, não pode ser considerada como açúcar, nem fonte de energia. Contribui com a textura, melhorando a sensação do produto ao ser degustado e também melhora a estabilidade de espumas e emulsões (BORNET, 1994; CÂNDIDO; CAMPOS, 1996). Em altas concentrações (15-25\% em água), a inulina tem propriedades de gel. Quando submetida a misturas sob alta agitação, forma um gel estável ou creme que pode ser facilmente incorporado em alimentos para substituir a gordura (NEVEN, 2001). É moderadamente solúvel em água (10\% em temperatura ambiente), sendo muito solúvel a $50-60{ }^{\circ} \mathrm{C}$, o que permite sua incorporação em sistemas aquosos nos quais a precipitação de outras fibras poderia ser um problema (BORNET, 1994; CÂNDIDO; CAMPOS, 1996). Não cristaliza, não precipita, e nem deixa sensação de secura ou areia na boca. Não é degradada durante a maioria dos processos de aquecimento.

A inulina vem sendo incorporada em diversos produtos alimentares, dentre eles, produtos de panificação e confeitaria. Em bolos, melhora as características reológicas, o que permite obter produtos leves, facilmente mastigáveis, que apresentam textura porosa e que são normalmente muito saborosos (LEITÃO et al., 1984). Controla a viscosidade desses produtos, de pudins e, particularmente, de massas com baixos teores de gordura (OLIVEIRA et al., 2004). No pão, apresenta uma série de vantagens tecnológicas, tais como o aumento da estabilidade da massa, sabor neutro, aumento de volume do pão, uniformidade da estrutura do miolo e melhora na habilidade de fatiamento. Tanto em pães quanto em produtos de cereais, modula a absorção de água, baseado na sua capacidade de se ligar à água, aumentando a vida de prateleira dos produtos.

Em relação ao desenvolvimento de novos produtos, o método Quality Function Deployment, QFD, denominado de Desdobramento da Função Qualidade, tem sido utilizado como um meio de operacionalizar e gerenciar as atividades do processo de desenvolvimento. O QFD é o desdobramento, passo a passo, das funções ou operações que compõem a qualidade do produto. A metodologia busca a solução antecipada dos problemas inerentes ao processo de desenvolvimento de produtos, a fim de que os pontos críticos que determinam a qualidade do produto e do processo de fabricação sejam estabelecidos já na fase de concepção e controlados durante os estágios do desenvolvimento do produto (CHENG; MELO FILHO, 2007).

A metodologia também assegura a obtenção da qualidade porque trabalha com foco nas necessidades dos consumidores. A matriz da qualidade é a ferramenta utilizada para organizar e dispor, em informações técnicas, as necessidades dos consumidores. Mais especificamente, ela inicialmente traduz as exigências dos consumidores, detectadas através de pesquisa de mercado, em linguagem técnica, ou seja, em parâmetros de qualidade do produto. As demais matrizes são decorrentes da matriz da qualidade e visam detalhar o projeto de forma que todos os fatores que contribuem para a obtenção do produto final sejam projetados, como, características dos produtos intermediários, parâmetros do processo de fabricação, matérias-primas e insumos. A metodologia permite ainda avaliar a satisfação do mercado alvo ao longo do processo de desenvolvimento do produto (CHENG; MELO FILHO, 2007).

Além disso, o método QFD auxilia a gestão do processo de desenvolvimento de produtos porque coordena o fluxo de informações e organiza as atividades no nível de funções. Promove assim, a integração interfuncional e a resolução rápida de problemas (AKAO, 1996; CHENG; MELO FILHO, 2007).

Dentro desse contexto, o objetivo deste trabalho foi o de desenvolver uma massa alimentícia pronta para o consumo com função prebiótica. A finalidade é atender às necessidades do consumidor que busca um produto inédito no mercado e que, além de prático, contribua com efeitos benéficos ao organismo humano. Para desenvolver tal produto, o método QFD foi utilizado, na tentativa de traduzir os desejos do mercado em características técnicas do produto e de suas matérias-primas.

\section{Material e métodos}

Foram preparadas duas formulações de massas de tortas (Tabela 1). Na primeira formulação (A), a massa foi preparada com água, farinha de trigo $\left(\right.$ Vilma $\left.^{\circledR}\right)$, inulina $\left(\right.$ Orafti $\left.^{\circledast}\right)$, manteiga sem sal (Itambé ${ }^{\oplus}$ ), ovo e sal. Na segunda formulação (B), objetivando-se uma massa mais leve e sabendo-se que a inulina é capaz de substituir a gordura, reduziu-se à metade a quantidade de manteiga. Assim foi necessário adicionar maior quantidade de água à formulação. Primeiramente foram misturados na masseira $\left(\right.$ Lieme $^{\circledast}$ ) a farinha de trigo, o sal e a inulina. Em seguida, adicionaram-se a manteiga sem sal, o ovo e a água,

Tabela 1. Formulações desenvolvidas.

\begin{tabular}{lrc}
\hline \multicolumn{1}{c}{ Ingredientes } & $\mathrm{A}$ & $\mathrm{B}$ \\
\hline Água & $5 \mathrm{~mL}$ & $25 \mathrm{~mL}$ \\
Farinha de trigo peneirada & $200 \mathrm{~g}$ & $200 \mathrm{~g}$ \\
Inulina & $25 \mathrm{~g}$ & $25 \mathrm{~g}$ \\
Manteiga sem sal & $100 \mathrm{~g}$ & $50 \mathrm{~g}$ \\
Ovo líquido & $50 \mathrm{~g}$ & $50 \mathrm{~g}$ \\
Sal & $2 \mathrm{~g}$ & $2 \mathrm{~g}$ \\
\hline
\end{tabular}


que foi acrescentada aos poucos. Realizou-se o boleamento da massa que, a seguir, foi refrigerada por 30 minutos a $4{ }^{\circ} \mathrm{C}$. A massa foi dividida em porções para em seguida ser cilindrada e colocada em fôrmas redondas de alumínio (Rochedo ${ }^{\circledR}, 18 \mathrm{~cm}$ ). As massas foram assadas a $180{ }^{\circ} \mathrm{C}$ por 15 minutos.

A composição centesimal foi determinada segundo os métodos descritos na AOAC (1995). A umidade foi determinada pelo método de secagem em estufa ventilada (MARCONI) a $105^{\circ} \mathrm{C}$ por 6 horas e as cinzas, por incineração em mufla (MAGNU'S) a $600^{\circ} \mathrm{C}$. Os lipídios foram extraídos com éter de petróleo e éter etílico, segundo método de Soxhlet modificado (QUIMIS); as proteínas foram determinadas pelo método de micro-Kjedahl e os carboidratos por diferença. $O$ fator de conversão de nitrogênio para proteína usado foi de 6,25.

\subsection{Elaboração da matriz de qualidade do produto acabado}

A metodologia do QFD foi utilizada para desenvolver o produto final e para definir os parâmetros de qualidade das matérias-primas.

Para conhecer as necessidades do mercado alvo em relação à massa para tortas, realizou-se uma pesquisa de mercado por meio de entrevista semiestruturada (ANEXO) na cidade de Belo Horizonte - MG, com uma amostra de trinta possíveis consumidores do produto. Na entrevista foram avaliadas as características que estes esperavam encontrar na massa da torta através do desdobramento de cenas da maneira, lugar e circunstâncias em que gostariam de consumir o produto, conforme sugestão de Cheng e Melo Filho (2007).

Com as informações obtidas, listou-se o maior número possível de desejos do consumidor, transformando-os em qualidades exigidas. Um exemplo dessa conversão foi quando um entrevistado pontuou que "a massa da torta deveria ser usada tanto para tortas salgadas quanto para doces”, e a tradução desse dado primitivo para um item exigido foi: "a massa tem que ter sabor neutro".

Construiu-se a tabela de desdobramento das qualidades exigidas a partir do agrupamento dessas informações em diferentes aspectos sensoriais do produto.

A partir das qualidades exigidas listadas foram extraídas as características técnicas do produto acabado. As informações obtidas através do mercado consumidor foram convertidas para o seu aspecto tecnológico, utilizando-se o raciocínio "Como a qualidade exigida poderia ser avaliada no produto final?", obtendo-se os atributos físico-químicos, microbiológicos e sensoriais do produto acabado. Parte da Matriz da Qualidade da massa funcional pronta para tortas obtida está apresentada na Figura 1. Fez-se uma correlação entre as qualidades exigidas pelo mercado e as características de qualidade do produto acabado, atribuindo-se valores 3,6 ou 9, que significam correlação fraca, média ou forte, respectivamente. A inexistência desses valores significa a ausência de correlação.

\section{Qualidade planejada e análise sensorial}

O grau de importância das qualidades exigidas foi estabelecido através de pesquisa com trinta e dois possíveis consumidores, na qual o entrevistado indicou o quanto cada característica era importante, numa escala de 1 (sem importância) a 5 (muito importante). As medianas para cada atributo foram lançadas na matriz.

Os produtos desenvolvidos foram avaliados sensorialmente através do Teste Afetivo de Aceitabilidade, por meio de escala hedônica estruturada de 9 pontos, com a participação de cinquenta provadores não treinados, apreciadores do produto. Aos julgadores foi solicitado que avaliassem as amostras da massa assada pura, sem recheios, com relação aos atributos inicialmente listados como importantes para o mercado alvo.

As medianas dos atributos avaliados na análise sensorial dos produtos desenvolvidos foram inseridas na matriz. Para comparar o desempenho dos produtos desenvolvidos em relação a cada qualidade exigida, empregou-se o teste estatístico não paramétrico de Mann e Whitney (SIEGEL; CASTELLAN Jr, 2006) com a finalidade de distinguir qual foi o preferido.

Os valores da qualidade planejada foram determinados utilizando-se novamente a escala hedônica de 1 a 9, de acordo com os valores sugeridos pelos elaboradores do produto. Para isso, foram levados em consideração os valores do grau de importância e as medianas calculadas após a análise sensorial.

O índice de melhoria foi calculado através da razão entre os valores da qualidade planejada pelo desempenho do produto na análise sensorial.

Após a análise do grau de importância e do nível de desempenho do produto, estabeleceram-se quais qualidades exigidas deveriam ser consideradas como argumentos de venda forte, médio ou fraco, ou seja, quais atributos seriam atrativos ao mercado, quais seriam itens de atração intermediária e quais seriam atributos óbvios ou obrigatórios ao produto. Os itens considerados atrativos ao mercado receberam a nota 1,5 ; itens intermediários, o valor 1,2; e àqueles considerados óbvios atribui-se o valor 1,0 .

O peso absoluto foi calculado pela multiplicação do grau de importância pelo índice de melhoria e também pelo argumento de venda. $O$ peso relativo de cada qualidade exigida é a porcentagem correspondente do peso absoluto.

\section{Qualidade projetada}

A Qualidade Projetada (parte inferior da matriz) foi determinada calculando-se o peso absoluto e o peso relativo das Características da Qualidade. O peso absoluto das Características da Qualidade foi calculado pelo somatório dos produtos dos pesos relativos das Qualidades Exigidas pelos valores numéricos das correlações. $\mathrm{O}$ peso relativo de cada característica da qualidade é a porcentagem correspondente do peso absoluto.

Estabeleceram-se as especificações físico-químicas, microbiológicas ou sensoriais para cada característica de qualidade do produto acabado. Esses valores foram armazenados na parte inferior da matriz de qualidade da massa, Figura 1. As especificações 


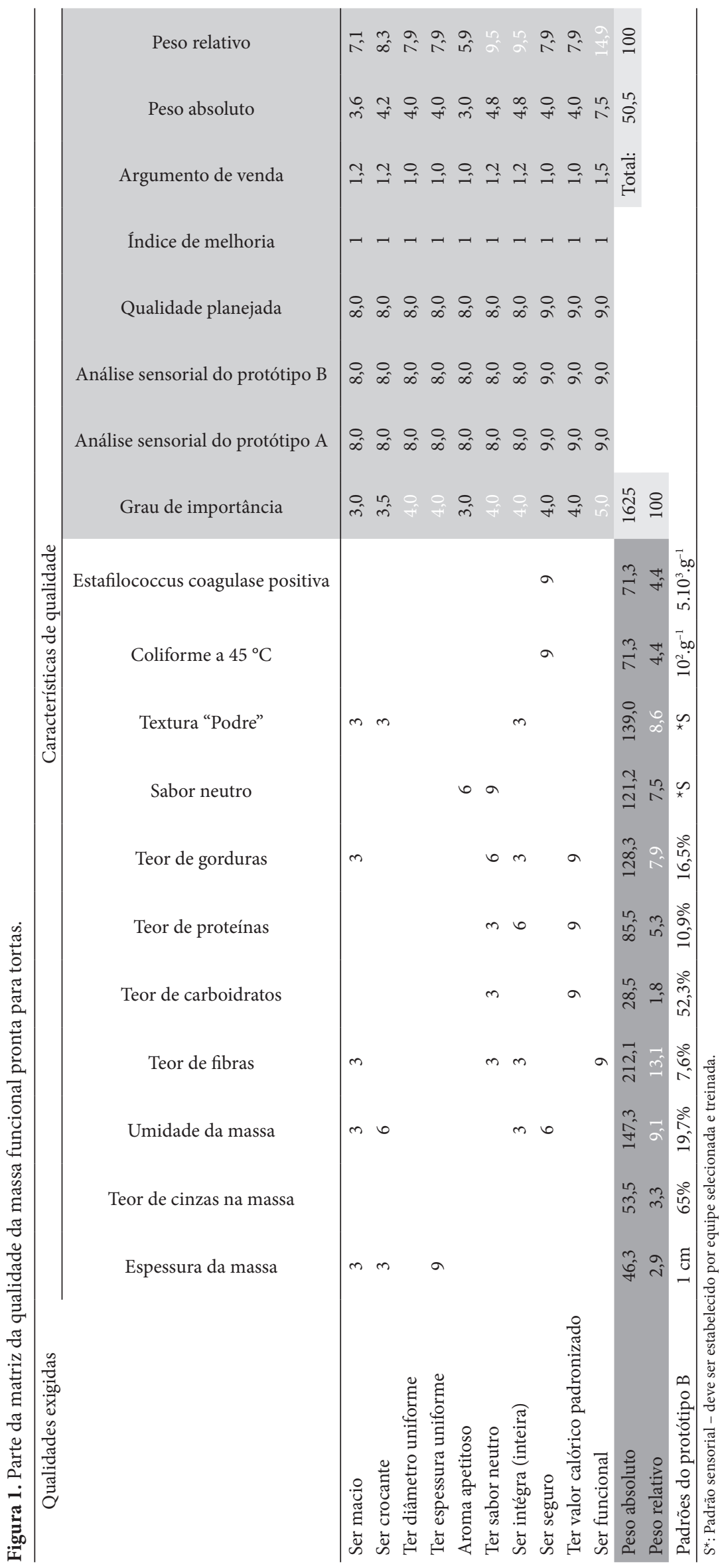


físico-químicas foram obtidas por análises laboratoriais como descrito anteriormente. Os padrões microbiológicos foram estabelecidos de acordo com a RDC n¹2/01 da Agência Nacional de Vigilância Sanitária (ANVISA) e os sensoriais devem ser julgados por uma equipe selecionada e treinada.

\subsection{Elaboração da matriz da qualidade das matérias-primas}

Inicialmente foram extraídas as características de qualidade das matérias-primas e dos ingredientes a partir das características de qualidade do produto acabado. Assim, foram listados todos os atributos, ou seja, todas as características físico-químicas, microbiológicas e sensoriais das matérias-primas que poderiam contribuir com a qualidade da massa para tortas.

Fez-se uma correlação entre essas qualidades e as características de qualidade do produto acabado, atribuindo-se valores 3, 6 ou 9, que significam correlação fraca, média ou forte respectivamente (Figura 2 ).

Calculou-se o peso de cada característica de qualidade do produto acabado somando-se os valores numéricos das correlações em cada coluna. Já o peso relativo de cada característica de qualidade é a porcentagem correspondente do peso absoluto.

Em seguida, o valor do peso relativo foi multiplicado pelo valor de cada correlação e esses produtos, somados horizontalmente. Os valores foram armazenados na coluna de peso absoluto. O peso relativo de cada característica de qualidade das matérias-primas é a porcentagem correspondente do peso absoluto.

Estabeleceram-se também as especificações físico-químicas, microbiológicas e sensoriais para cada característica de qualidade das matérias-primas. Tais valores estão armazenados na área lateral da matriz de matérias-primas, Figura 2. As especificações da farinha de trigo e demais ingredientes utilizados foram obtidas dos fornecedores. Os padrões microbiológicos, por meio da RDC n²12/01 da Agência Nacional de Vigilância Sanitária e os sensoriais devem ser julgados por uma equipe selecionada e treinada (BRASIL, 2001).

\section{Resultados e discussão}

Observando-se a matriz da qualidade da torta (Figura 1), ao se comparar estatisticamente os resultados das análises sensoriais dos protótipos $\mathrm{A}$ e $\mathrm{B}$, verificou-se que não houve diferença significativa entre eles no nível de 5\% de significância, optando-se então por adotar os padrões de qualidade do produto B pelo fato deste ter valor calórico reduzido em relação ao produto A. Observa-se na matriz que os atributos avaliados na análise sensorial obtiveram notas a partir de 8 , o que significa que os provadores gostaram muito do produto.

As qualidades exigidas mais importantes para o públicoalvo foram: ser funcional, ser uma massa íntegra, ou seja, que não quebre, de sabor neutro e com diâmetro e espessura uniformes.

Como o produto foi bem aceito, todos os atributos receberam nota 1 no índice de melhoria, o que significa que não se planejou nenhuma melhoria no produto. No entanto, as qualidades exigidas - ter sabor neutro, ser íntegra e funcional necessitam de maior atenção da equipe de desenvolvimento por serem médios ou fortes argumentos de venda e apresentarem alto grau de importância para o público alvo.

Verifica-se também, através dos resultados da matriz, que as características de qualidade que apresentaram maiores pesos relativos foram as análises do teor de fibras, do teor de gorduras, umidade e da textura "podre", o que indica que essas características de qualidade devem ser priorizadas no controle da qualidade do produto.

Através da matriz das matérias-primas (Figura 2), observa-se que as características de qualidade que devem ser mais controladas para garantir a qualidade do produto acabado são o farinograma da farinha de trigo, a quantidade de manteiga e de ovo líquido, por serem as características dos ingredientes que mais influenciam nas características de qualidade do produto acabado.

Em relação às contribuições do método QFD para o desenvolvimento do novo produto, destaca-se que a construção das matrizes e as discussões inerentes a esta atividade proporcionaram uma melhor percepção das relações entre as características de qualidade do produto final e os parâmetros de controle da qualidade das matérias-primas.

Os testes de aceitação e as pesquisas de mercado, necessárias à elaboração da matriz de qualidade da massa, foram importantes para demonstrar que informações valiosas podem ser extraídas das opiniões dos consumidores.

Da mesma forma, Miguel et al. (2007) utilizaram a metodologia do QFD para avaliar o perfil do consumidor de abacaxi "Pérola", destacando que o método também foi útil na identificação dos atributos de qualidade que eram decisivos no momento da compra, assim como para estabelecer o grau de importância de cada atributo exigido pelo mercado e para a interpretação da análise sensorial do abacaxi. Chaves (2002) e Cortés e Da Silva (2005) aplicaram a metodologia na melhoria de um iogurte e concluíram que o método também foi importante para traduzir os desejos dos clientes e para reestruturar o produto segundo as expectativas do mercado. Tumelero et al. (2000) aplicaram o QFD em uma linha de fabricação de biscoitos salgados com o objetivo de melhorar o produto. O QFD foi responsável por apontar itens que deveriam ser melhorados nos testes sensoriais do produto, nas pesquisas de mercado e quais características de qualidade deveriam ser mais bem avaliadas no produto. Em relação ao processo de fabricação, a metodologia também foi responsável por apontar as etapas do processo que necessitavam de melhorias e de métodos mais adequados de controle.

Em outros trabalhos, publicados por Miguel et al. (2003), os autores apontam outras contribuições do QFD, não relacionadas à interpretação das matrizes como nesse trabalho, mas como meio de sistematizar o processo de desenvolvimento de produtos em nível gerencial, contribuindo para organizar as atividades inerentes ao processo. Também Marcos (2001), aponta como benefícios resultantes da aplicação do método para desenvolvimento de tomate de mesa, uma maior interação das áreas funcionais envolvidas no processo de desenvolvimento e uma ferramenta útil para se estabelecer as estratégias de vendas a partir da análise do mercado consumidor. 


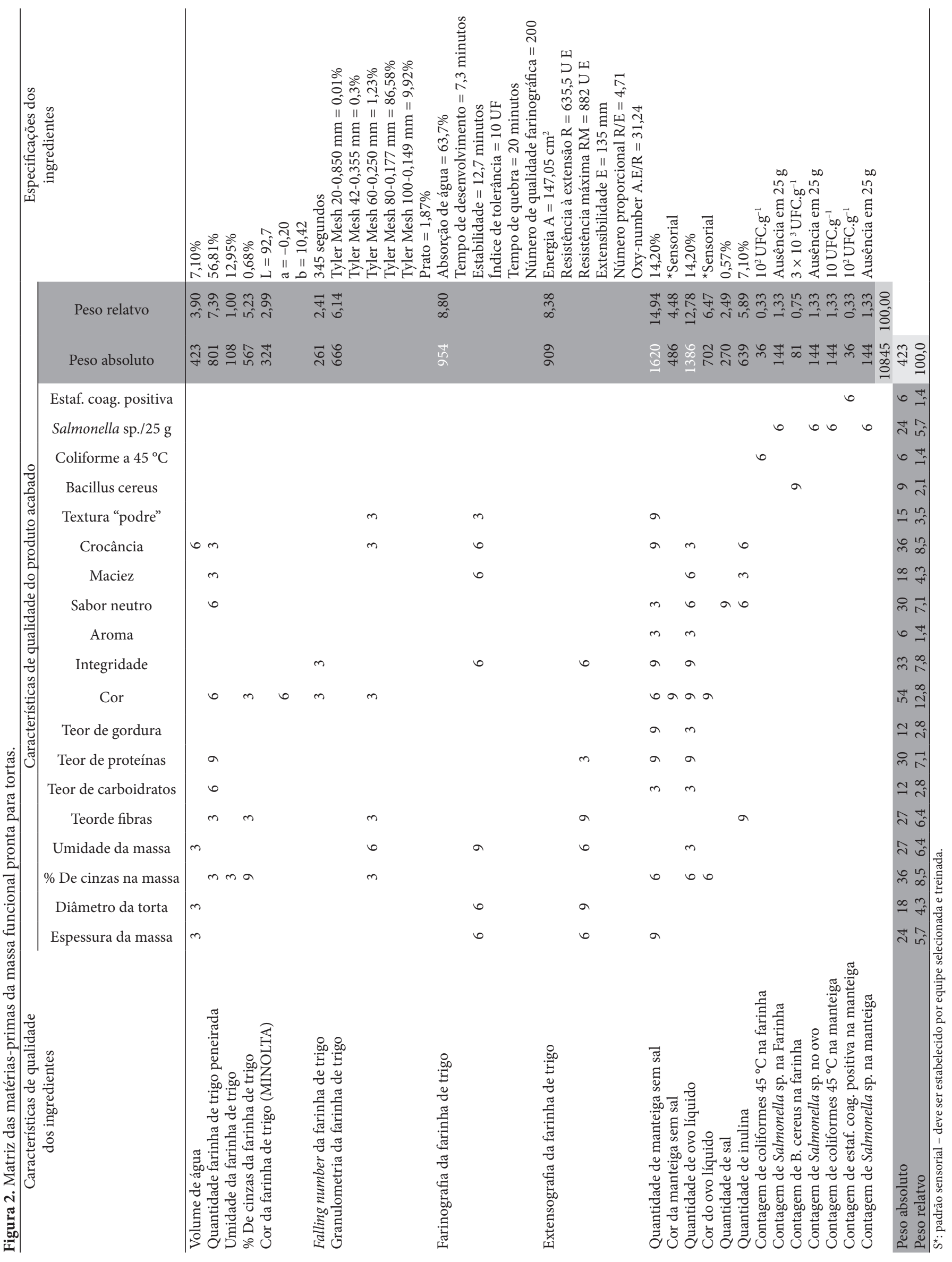




\section{Modelo da pesquisa de mercado}

1) Você tem o hábito de comprar massa pronta para tortas?

2) Com qual frequência compra massas para o preparo de tortas?

3) Por que você compra esse tipo de produto? (Qual é a sua motivação na compra?)

4) Quais são os principais problemas já encontrados nesse tipo de produto?

5) Se você fosse adquirir uma massa para torta pronta, quais características você desejaria encontrar nesse produto? Marque as opções desejadas e escreva outra se lhe interessar.
( ) Ter sabor neutro
( ) Ter sabor doce
( ) Ter sabor salgado
( ) Ter cor próxima ao creme/bege
( ) Ser macia
( ) Ser crocante
( ) Ser uma massa "podre" (dissolve fácil na boca)
( ) Ter tamanho uniforme
( ) Não quebrar
( ) Ser segura (não causar danos à saúde)

Outras:

6) Você sabe o que é um alimento funcional? Você gostaria de adquirir uma massa que tivesse algum benefício sobre a saúde?

7) Além da torta já estar pronta, se ela tivesse o benefício de promover saúde, você a compraria com maior frequência?

\section{Conclusões}

O desdobramento das matrizes, a partir da demanda dos consumidores, identificadas nas pesquisas de mercado, permitiu priorizar os atributos de controle de qualidade do produto final e das matérias-primas. Assim, a massa desenvolvida nesse trabalho foi bastante apreciada, como demonstrado nos resultados da análise sensorial.

\section{Referências bibliográficas}

AKAO, Y. Introdução ao desdobramento da qualidade. Belo Horizonte: Fundação Christiano Ottoni, 1996. 187 p.

ASSOCIATION OF OFFICIAL AGRICULTURAL CHEMISTS AOAC. Official methods of analysis of AOAC international. 16. ed. Arlington: AOAC International, 1995. 2v.

BORNET, F. R. J. Undigestible sugars in food products. American Journal of Clinic Nutrition, v. 59, n. 3, Suppl, p. 763S-769S, 1994.

BRASIL. Agência Nacional de Vigilância Sanitária - ANVISA. Portaria no 27, de 13 de janeiro de 1998: regulamento técnico referente à informação nutricional complementar. Brasília, DF, 1998. Disponível em: <http://www.anvisa.gov.br>. Acesso em: 26 nov. 2007.

BRASIL. Agência Nacional de Vigilância Sanitária - ANVISA. Portaria $n^{\circ}$ 15, de 30 de abril de 1999: institui junto à Câmara Técnica de Alimentos, a Comissão de Assessoramento Tecnocientífico em Alimentos Funcionais e Novos Alimentos. Brasília, DF, 1999. Disponível em: <http://www.anvisa.gov.br>. Acesso em: 26 nov. 2007.

BRASIL. Agência Nacional de Vigilância Sanitária - ANVISA. Resolução RDC no $^{\circ}$ 12, de 2 de janeiro de 2001: regulamento técnico sobre padrões microbiológicos para alimentos. Brasília, DF, 2001. Disponível em: <http://www.anvisa.gov.br >. Acesso em: 19 dez. 2007.

CÂNDIDO, L. M. B.; CAMPOS, A. M. Alimentos para fins especiais: dietéticos. São Paulo: Varela, 1996. 423p.

CHAVES, O. Aplicação do método de desdobramento da função qualidade na industrialização do leite de consumo em Minas Gerais. 2002. 86 p. Dissertação (Mestrado em Economia Rural) Departamento de Economia Rural, Universidade Federal de Viçosa, Viçosa, 2002.

CHENG, L. C.; MELO FILHO, L. D. R. QFD: desdobramento da função qualidade na gestão de desenvolvimento de produtos. São Paulo: Editora Blucher, 2007. 539p.

CORTÉS, D. M. M.; DA SILVA, C. A. B. Revisão: Desdobramento da Função Qualidade - QFD - conceitos e aplicações na indústria de alimentos. Brazilian Journal Food Technology, v. 8, n. 3, p. 200-209, 2005.

GIBSON, G. R.; ROBERFROID, M. Dietary modulation of the human colonic microbiota: introducing the concept of prebiotics. Journal of Nutrition, v. 125, n. 6, p. 1401-1412, 1995. 
LEITÃO, R. F. F. Estudos de duas cultivares de triticale e sua aplicação em produtos de massas alimentícias (macarrão, biscoito e bolos). Boletim ITAL, v. 21, n. 3, p. 325-334, 1984.

MARCOS, S. K. Desenvolvimento de tomate de mesa com o uso do método QFD (Quality Function Deployment), comercializado em um supermercado. 2001. 199 f. Tese (Doutorado em Ciência de Alimentos) - Universidade Estadual de Campinas, Campinas, 2001.

MIGUEL, A. C. A. et al. Aplicação do método QFD na avaliação do perfil do consumidor de abacaxi "Pérola". Ciência e Agrotecnologia, v. 31, n. 2, p. 563-569, 2007.

MIGUEL, P. A. C. et al. Desdobramento da qualidade no desenvolvimento de filmes flexíveis para embalagens. Polímeros: Ciência e Tecnologia, v. 13, n. 2, p. 87-94, 2003.

NEVEN, E. Inulina e Oligofrutose: ingredientes multifuncionais para o desenvolvimento de produtos lácteos. Leite e Derivados, v. 11, n. 61 , p. 32-37, 2001.
OHTA, A. et al. Effects of fructooligosaccharides on the absorption of iron, calcium and magnesium in iron-deficient anemic rats. Journal of Nutritional Science and Vitaminology, v. 41, p. 281-291, 1995.

OLIVEIRA, R. A. et al. Otimização de extração de inulina de raízes de chicória. Revista Brasileira de Produtos Agroindustriais, v. 6, n. 2, p. 131-140, 2004.

SIEGEL, S.; CASTELLAN JR, N. J. Estatística não-paramétrica para ciências do comportamento. 2 ed. Porto Alegre: Artmed, 2006. $448 \mathrm{p}$.

TUMELERO, N.; RIBEIRO, J. L. D.; DANILEVICZ, A. M. F. O QFD como ferramenta de priorização para o planejamento da qualidade. In: CONGRESSO BRASILEIRO DE GESTÃO DE DESENVOLVIMENTO DE PRODUTO, 2., 2000, São Carlos, SP. Anais... São Carlos: UFSCar, 2000. 